ISSN 1518-3483

Licenciado sob uma Licença Creative Commons

\title{
A estética na formação de professores
}

\author{
The aesthetic in the formation of teachers
}

Adair de Aguiar Neitzel[a], Carla Carvalho[ ${ }^{[b]}$

[a] Doutora em Literatura pela Universidade Federal de Santa Catarina (UFSC), professora do Programa de Pós-Graduação em Educação da Universidade do Vale do Itajaí (Univali), líder do grupo de pesquisa Cultura, Escola e Educação Criadora da mesma universidade, Itajaí, SC - Brasil, e-mail: neitzel@univali.br

[b] Doutora em Educação pela Universidade Federal do Paraná (UFPR), professora do Programa de Pós-Graduação em Educação da Universidade do Vale do Itajaí (Univali), Itajaí, SC - Brasil, e-mail: ca.carvalho@terra.com.br

\section{Resumo}

Esta pesquisa aborda questões relacionadas à formação estética do professor. Partiu-se da hipótese de que a formação estética interfere na sua forma de agir em sala de aula, pois possibilita um olhar mais sensível aos problemas educacionais. Esta pesquisa investigou junto aos professores dos anos iniciais da rede municipal do Balneário Piçarras (SC), Brasil, como a sua participação em encontros de formação estética por meio das artes interferiu no seu fazer pedagógico. O objetivo geral foi analisar o impacto das atividades de formação estética promovidas na formação continuada de professores na sua prática pedagógica, utilizando a abordagem qualitativa. Na coleta dos dados, propuseram-se três ações: a) análise dos documentos norteadores do projeto; b) aplicação de um instrumento para delinear o perfil dos professores; c) aplicação de questionários aos professores. Esses dados demonstraram que, por meio do ensino de arte, houve contribuições no campo do conhecimento, sendo que $50 \%$ indicaram mudanças no currículo e 
100\%, no repertório. Ainda, 90\% evidenciaram que as vivências artísticas favoreceram a construção de novas estratégias, possibilidades e subsídios para as atividades realizadas em sala de aula.

Palavras-chave: Formação de professores. Cultura. Estética. Arte.

\section{Abstract}

This research addresses issues related to the aesthetic formation of the teacher. Start form assuming that the aesthetic formation of teachers interferes in their behavior in the classroom, allowing a more sensitive view to educational problems. This research investigated the teachers in the early years, the municipal schools of Piçarras city (SC), Brazil, and how their participation in meetings of aesthetic education through the arts interfered in their teaching. The main objective was to analyze the impact of aesthetic formation activities promoted in the continued education of teachers in their pedagogic practice. This is survey of qualitative approach. In data collection we propose three actions: a) analysis of documents that guides the project, b) application of an instrument to delineate the profile of teachers, c) questionnaires application to teachers. These showed that through teaching art there were contributions in the field of knowledge, of which $50 \%$ reported changes in curriculum and 100\% in the repertoire. Still, 90\% showed artistic experiences favored the new strategies, opportunities and subsidies for the classroom activities construction.

Keywords: Teacher formation. Culture. Aesthetics. Art.

\section{Introdução}

Eu ia para a escola todos os dias de manhã e quando chegava logo, logo, eu tinha que me meter no vidro. É, no vidro! Cada menino ou menina tinha um vidro e o vidro não dependia do tamanho de cada um, não! O vidro dependia da classe que a gente estudava. [...] A gente não escutava direito o que os professores 
diziam, os professores não entendiam o que a gente falava... (ROCHA, 2011).

Quando a escola é de vidro (ROCHA, 2011) é um texto que nos permite pensar sobre a forma como se aprende na escola e, em particular, sobre a formação docente. De acordo com Nóvoa (1995), esta é o resultado de um processo identitário que corresponde a uma construção ao longo da vida e da carreira de professor, no qual há de se considerar que os saberes da docência são compostos por saberes da experiência, do conhecimento e pedagógicos. Por isso, a trajetória individual de cada professor e a história das práticas sociais e educativas precisam ser consideradas, pois a apropriação desses saberes por parte dos docentes é resultado de um processo histórico e, como tal, sujeito a diversas implicações (ZIBETTI; SOUZA, 2007). Portal e Franciscone (2007, p. 559), nesse sentido, indicam a necessidade de a formação continuada ser mais ampla, "fundamentada em uma nova visão de mundo, comprometida com a formação humana, na sua integralidade/inteireza", afastando-se da ideia de cursos e palestras voltados estritamente para a superação de determinados problemas específicos do ato de ensinar e aprender.

Duarte Jr. (2001) provoca-nos a pensar na necessidade de uma educação estética que se ocupe com o refinamento dos nossos sentidos, de a escola ser um espaço não apenas do conhecimento intelectivo, mas também de um saber sensível. Essa compreensão revela uma concepção de educação como um processo formativo do humano que colabora no desenvolvimento dos sentidos e significados fundamentais para apropriação de uma sensibilidade que permita uma percepção mais apurada do mundo, sendo essa sensibilidade adquirida por meio de um processo que o próprio sujeito estabelece nas suas relações e que o faz desenvolver seus sentidos.

A busca pelo conhecimento dá-se por diversas vias e uma delas é pelo acesso aos bens culturais. Por meio da arte, o sujeito amplia sua capacidade de reflexão e percepção, assim como sua sensibilidade. Vigotski (1999, p. 35) afirma que "o que não estamos em condição de compreender 
diretamente podemos compreender por via indireta, através da alegoria, e toda a ação psicológica da obra de arte pode ser integralmente resumida ao aspecto indireto dessa via". Nesse sentido, na relação com a arte, o sujeito pode indiretamente se relacionar consigo mesmo, ampliar sua rede de compreensão do que o rodeia. A experiência estética pode ser um meio pelo qual o sujeito percebe melhor a si mesmo e seu entorno.

Segundo Carvalho e Bufrem (2006, p. 56), esse desenvolvimento dos sentidos humanos é o elemento principal no processo de humanização e o indivíduo, "ao entrar em contato com as experiências artísticas, traz todo o conhecimento adquirido ao longo de sua vida [...] a arte neste contexto é parte da cultura e lhe permite experimentar, por meio dos seus sentidos, situações inusitadas". Observar-se e tomar consciência de seus saberes pode possibilitar ao professor ter conhecimento de suas escolhas, perceber-se em formação pedagógica e pessoal. Com isso, a formação estética é um possível caminho pelo qual o professor pode ampliar suas experiências pessoais e profissionais.

Considerando que a formação estética do professor interferirá na sua forma de agir em sala de aula, pois possibilitará um olhar mais sensível aos problemas educacionais, esta pesquisa investigou junto aos docentes da rede municipal do Balneário Piçarras (SC), Brasil, como a participação em encontros de formação estética por meio das artes interferiu na forma de lidar com o aluno e organizar suas ações pedagógicas. O objetivo geral foi analisar o impacto das atividades de formação estética promovidas na formação continuada de professores na sua prática pedagógica.

Em contato com diversas vivências artísticas, os professores podem ter novas experiências e, por meio delas, sensibilizar-se e refletir sobre sua atuação no meio escolar. Ao ter acesso a bens imateriais, ao apreciar uma obra de arte, o sujeito "fruidor" reflete sobre si mesmo, sobre o mundo e, consequentemente, sobre as suas ações. A apreciação artística, portanto, leva o sujeito a perceber-se no contexto em que está inserido, podendo esse movimento levá-lo a enxergar também o outro, num processo de autoconhecimento que o auxiliará a desenvolver seus sentidos e ampliar significados. 


\section{Contextualização da pesquisa}

Observa-se que a educação estética por meio da arte é relevante na formação do professor, pois, à medida que ele passa a ter contato com a arte como "fruidor", torna-se um profissional que percebe o seu entorno de forma diferente. Essa relação entre "fruidor" e objeto artístico pode auxiliá-lo na mediação que efetua no processo de ensino-aprendizagem, ampliando a visão de um professor que, por meio da apropriação de uma sensibilidade estética, consegue entrever outras possibilidades de ensino e aprendizagem, centradas no dinamismo, na criatividade, na pesquisa. Por meio da formação estética, amplia-se a formação cultural e humanística, que irá corroborar o seu papel de mediador e ampliar seus horizontes cognitivos e sua sensibilidade e capacidade perceptiva em relação ao fenômeno artístico e a questões de formação geral.

Observa-se na literatura que a relação entre obra e "fruidor" implica a formação e atuação do professor em sala de aula:

A arte possibilita ao educador construir uma prática pedagógica em que conhecimento, imaginação e expressão conjugam-se dinamicamente, beneficiando o desempenho do estudante, favorecendo o desenvolvimento da imaginação e das habilidades, o exercício da criatividade, do senso crítico e da melhor absorção do conteúdo das aulas (CARVALHO; BUFREM, 2006, p. 48).

Com base nesses fundamentos, promovemos esta pesquisa de abordagem qualitativa, partindo de análise documental, sendo que, para coleta de dados, realizamos três ações básicas:

a) análise dos documentos norteadores do projeto de formação da rede municipal, a saber: objetivos, concepção, metodologia e matriz curricular do projeto;

b) aplicação de instrumento para compor o perfil sociocultural e profissional dos professores; 
c) aplicação de questionário, composto por perguntas fechadas e abertas, para identificar como a participação em encontros de formação estética por meio das artes interferiu na atuação do professor em sala de aula.

O critério para escolha dos professores foi a assiduidade (mínimo de 75\%) nas formações, que ao todo totalizaram 360 horas, durante dois anos. Para a análise dos questionários, adotamos a metodologia de conteúdo de Rose (2003), que prevê o delineamento de um referencial de codificação, a mecânica da codificação e a construção de tabelas de frequência para a análise de conteúdo.

Para apontar com mais clareza e precisão o impacto das atividades propostas na prática pedagógica do professor, estabelecemos, após analisar suas falas, as seguintes categorias:

a) categoria $\mathrm{A}$ : mudanças que as experiências artísticas trouxeram no currículo da escola e no repertório do professor;

b) categoria B: atividades artísticas promovidas na escola;

c) categoria C: concepção do professor de arte;

d) categoria D: contribuições que as atividades trouxeram para a prática pedagógica.

Os sujeitos de pesquisa foram dez professores da rede municipal do Balneário Piçarras (SC), Brasil, que atuam nas séries iniciais do Ensino Fundamental, número que corresponde a $25 \%$ dos professores dessa categoria. A escolha por esse grupo justifica-se por esse município ter apresentado um programa de formação continuada com matriz curricular focada em vivências artísticas, desenvolvido ao longo de dois anos. Com relação ao perfil do grupo, a pesquisa revelou que $90 \%$ dos pesquisados têm a licenciatura concluída em Pedagogia, Habilitação em Educação Infantil e Séries Iniciais, e 10\%, isto é, um professor, estavam em processo de formação. $\mathrm{O}$ dado mostra que os professores que atuam nos anos iniciais 
adequaram-se à Lei de Diretrizes e Bases (BRASIL, 1996), que exige formação superior e não apenas o magistério em nível médio.

Essa formação soma-se à experiência dos profissionais, pois $50 \%$ deles atuam há mais de dez anos no magistério. Dos pesquisados, nenhum tem menos de um ano de atuação: 20\% trabalham entre 11 e 15 anos no magistério e 30\%, há mais de 15 anos. Dos outros 50\% dos professores envolvidos na pesquisa, $30 \%$ estão no magistério há menos de cinco anos e $20 \%$ atuam entre seis e dez anos. Outro fator relevante é que $60 \%$ dos entrevistados dedicam-se somente ao Ensino Fundamental, o que permite aos sujeitos de pesquisa focar seus estudos nas necessidades dos alunos dessa faixa etária de ensino. Por sua vez, 30\% atuam também no Ensino Fundamental e Educação de Jovens e Adultos e 10\%, na Educação Infantil e Educação de Jovens e Adultos.

Com relação à formação cultural do professor, buscamos identificar dados relacionados aos hábitos de leitura, à frequência com que vão a eventos culturais e ao cinema, àquilo que preferem assistir, além de seus gostos relacionados à música. No quesito leitura, os professores citaram quais os tipos de livro que mais liam, podendo optar por mais de uma alternativa. A preferência de leitura manteve-se entre os livros de literatura, educação, autoajuda, religiosos, científicos e, por último, apostilas. Tendo em vista que a literatura infantil é um material de leitura amplamente empregado nas séries iniciais, fica difícil identificar se a preferência dos professores é em decorrência desse uso. Já o fato de o grupo citar livros de educação como um dos materiais mais lidos demonstra que a leitura para esse grupo vem revestida de funcionalidade, pela sua função informativa e formativa. Em relação à quantidade, $40 \%$ leem de dois a três livros por semestre; $30 \%$, mais de seis livros; $20 \%$, de quatro a seis livros; e 10\%, apenas um livro, dado que revela um número de livros lidos bastante significativo, apontando para uma classe que privilegia a leitura.

No que diz respeito à participação do grupo em eventos culturais, $50 \%$ citaram ter participado, no período de dois anos, apenas de atividades desenvolvidas durante os cursos de formação promovidos pela 
rede, uma vez que a cidade não possui uma casa de espetáculos teatrais, cinema ou galerias de arte; apesar de o município de Itajaí, a 15 km, tê-las, $40 \%$ foram raramente ao cinema e $20 \%$, às vezes. Apenas $10 \%$ foram com frequência, ou seja, a ida ao cinema faz parte do cotidiano de poucos. Este é um público que mantém contato com o cinema por meio da televisão ou da locação de DVDs, tendo que se adequar à oferta de mercado: $28 \%$ optaram por comédias; $22 \%$ por romances; $17 \%$ por dramas; $11 \%$ por filmes de ação; e $5 \%$ por suspense. Os filmes de caráter educativo foram citados por apenas $6 \%$ dos entrevistados, seguidos de documentário, com $6 \%$, e épico, com $5 \%$. Esse perfil revela que a relação dos professores com os produtos estéticos dá-se de maneira bastante tímida e diversificada, porém são limitadas as condições de acesso. O único indicador que apresenta certo padrão é a questão da leitura, visto que essa atividade é intrínseca ao professor. Esses dados apontam a necessidade de incluir oportunidades de educação cultural nos programas de formação, ampliando o acesso do professor a exposições visuais, idas ao teatro, sessões de contação de histórias e de música.

Oliveira (2007) elaborou um estudo sobre o acesso aos bens estéticos partindo da problemática de que a atribuição de sentido aos códigos estéticos pela população afasta-a da obra. Segundo a autora, a população distancia-se da arte em grande parte não por não ter acesso, mas por não dominar os seus códigos. Nesse caso, temos que mencionar a importância do acesso à arte para que o público construa referenciais, pois, não tendo acesso, não há critérios de valoração da arte pautados em emoções ou em uma leitura intuitiva criada a partir de sentimentos individuais.

O acesso é o primeiro passo para a formação de um público. Isso se torna notório quando avaliamos a frequência com que os entrevistados ouviram música: $60 \%$ sempre e $30 \%$ quase sempre. Os estilos musicais mais citados foram MPB e música clássica, termo usado para generalizar a música erudita. Ainda, apareceram nas respostas: romântica (13\%), gospel (13\%), bossa-nova (6\%), sertaneja (6\%), blues (6\%) e todas (6\%). Percebemos, aqui, a convivência entre tendências musicais diversas, estando a música presente em distintas formas e formatos. Observamos 
como as pessoas transitam entre diferentes gêneros, o que vai alterando seu repertório e gosto, pois "a apreciação artística é um processo acumulativo; você descobre novos pontos de interesse, porém isso não quer dizer que precise negar o que gostava antes" (SCHAFER, 1991, p. 21).

Concluímos que o grupo tem acesso à música, mas isso não significa, como afirma Oliveira (2007), o domínio de seus códigos estéticos refinados, mesmo porque há uma pulverização com relação aos gêneros musicais ouvidos, o que é percebido pela variedade nas respostas. Além disso, é importante ressaltar que, apesar da grande expressão de ouvintes de músicas, esta é uma das temáticas menos utilizadas em sala de aula, como veremos a seguir, o que nos leva a constatar que, nesse caso, ela é vista apenas como entretenimento.

Esses dados mostram que o envolvimento dos professores com as linguagens artísticas ocorre principalmente por meio daquelas amplamente exploradas pela indústria cultural. Na concepção de Peixoto (2003), a lógica excludente do sistema capitalista distancia a arte do grande público, que é a classe trabalhadora, enfatizando a necessidade de se discutir a questão da acessibilidade nesse contexto.

\section{Análise dos dados: as contribuições para a prática pedagógica}

A arte tem função básica na formação do homem e não é apenas por meio de atividades de natureza lógica e objetiva que ele desenvolve as competências necessárias para atuar no meio profissional, pois "[...] a arte no processo criativo-fruitivo constitui fonte de humanização e educação do homem" (PEIXOTO, 2003, p. 94). Sendo o professor a variável fundamental para se efetivar o processo de ensino e aprendizagem, um programa de formação necessita, para além da formação profissional, considerar a formação cultural do professor. Essa premissa pretende, assim, ampliar a cultura pedagógica, levando em conta aspectos culturais que auxiliem a percepção do professor acerca dos envolvidos no processo de ensino-aprendizagem, de seus pares, da comunidade e do mundo que o rodeia, 
repensando os valores que o cercam, pois o sensível, o cognitivo e o ético são esferas essenciais para a formação do homem.

Ao serem abordados a respeito de quais contribuições as vivências artísticas e os estudos teóricos relacionados às artes trouxeram para a sua formação, $100 \%$ dos entrevistados afirmaram que houve muitos ganhos na área do conhecimento, pois puderam ampliar seus saberes a respeito dessas temáticas. Uma vez que essa bagagem contribui para a constituição da subjetividade do sujeito e, consequentemente, para a sua profissionalidade docente, é importante que o universo cultural seja ampliado para que se possa pensar numa educação estética. Além disso, 90\% desse grupo declarou que as temáticas favoreceram a construção de novas estratégias de ensino, auxiliando no planejamento e organização das atividades realizadas cotidianamente em sala de aula. "Uma nova estratégia para estar sendo usada em nosso cotidiano escolar. Para contribuir e facilitar ainda mais o processo de ensino e aprendizagem" (Sujeito 2).

Foram citadas atividades de música, artes visuais, teatro, dança e fantoches como propostas que passaram a fazer parte da rotina da sala de aula com mais frequência. Segundo Veiga (2009), se no contexto social os sujeitos não percebem os diversos espaços culturais de fácil acesso, cabe à escola planejar ações que possibilitem a integração entre escola e espaço cultural, no intuito de compreender que o currículo escolar não pode ser dissociado do contexto social. É interessante notar que 30\% referiram-se ao aumento do interesse dos alunos pelas aulas, assim como citaram que eles demonstraram com mais intensidade fazer uso da criatividade durante essas atividades. Nas respostas, os professores não deixaram claras as concepções de criatividade, mas indicaram que os alunos relacionaram-se mais criativamente com os conteúdos abordados. Observamos que os professores arriscaram-se em elaborar aulas diferenciadas e, com isso, os alunos responderam com mais envolvimento.

Num curso de formação continuada, nem sempre o que o professor busca é a novidade; em muitos casos, ele quer se certificar de suas ações, ou seja, busca a legitimação de suas práticas, como podemos observar na declaração a seguir: "não sabia a medida para ousar em sala de 
aula com essas propostas. Ficava tímida, fazia por minha conta e achava que podia estar exagerando. Agora sei que não estava errada, precisava de respaldo" (Sujeito 6). Essa fala traz à baila a realidade escolar: o professor encontra-se muitas vezes sem um interlocutor para expressar suas ideias e angústias, por isso a formação continuada deve cumprir o papel de ser um espaço de trocas entre os pares.

As declarações dos professores evidenciam que alguns já promoviam atividades artísticas no dia a dia, porém, por vezes, a falta de apoio teórico deixava-os inseguros de como introduzir esses elementos. Após os encontros de formação, $40 \%$ dos respondentes consideraram-se mais seguros em promover atividades que resultassem na formação estética dos seus alunos e suas falas apontam a relação entre o saber sensível e o conhecimento inteligível. "Contribuiu para melhor desempenho das atividades diárias em sala de aula, fazendo com que o aluno se concentre mais nas atividades propostas" (Sujeito 3).

Sabemos que o professor priorizará atividades artísticas em sala de aula se vivenciar experiências estéticas e obtiver domínio conceitual sobre essas áreas. Assim, questionados se houve ampliação do repertório artístico e cultural, $100 \%$ dos professores responderam afirmativamente, em especial por meio de atividades de campo, como visitas ao teatro e à igreja. Citaram ainda as atividades envolvendo música, contato com novos textos literários e a arte visual e cênica. Em outra questão, sobre as temáticas que mais colaboraram para a formação humana dos professores, todas as manifestações artísticas - música, literatura, teatro, cinema e folclore - foram citadas, demonstrando que cada professor teve uma percepção diferente sobre cada uma dessas temáticas.

A investigação também buscou verificar se houve alterações no cotidiano da instituição escolar, com base nas atividades trabalhadas no decorrer do curso. Dos respondentes, 50\% disseram não ter notado alterações no currículo da escola e no cotidiano e $20 \%$ afirmaram que essa mudança ocorreu isoladamente, apenas na sala de aula. Cabe aqui uma ponderação: esse grupo de professores não se sente participante da gestão da escola e percebe a sala de aula como um espaço distante da 
administração escolar. As atividades que o professor desenvolve em sala de aula não são percebidas por ele como atividades curriculares da escola. Por isso, ao serem indagados se houve alterações no currículo da escola, a resposta é negativa, pois segundo seu olhar a mudança ocorreu na sala, que é um espaço remoto da gestão escolar. Há por trás desse pensamento a negação do currículo constituído na ação, no cotidiano escolar.

Não há como desconhecer que toda ação humana gera uma transformação, seja ela de ordem simbólica, material ou psicossocial. Quem determinará as atividades culturais curriculares e extracurriculares que colaborarão na formação estética no e do contexto escolar? Numa gestão participativa, todos colaboram. Ademais, já afirmamos que o currículo escolar não deveria ser dissociado do contexto social, pois se entende que ele é o vivido na escola, aquilo que está registrado nos documentos, como as ações cotidianas e vividas. Assim, a formação cultural, artística e estética precisa ser contemplada no projeto pedagógico da escola.

Apesar de declararem que as temáticas vivenciadas melhoraram sua prática pedagógica e que eles passaram a desenvolver com mais intensidade atividades artísticas em sala de aula, ao serem questionados quais das atividades artísticas foram mais promovidas pela escola, $90 \%$ dos entrevistados indicaram a contação de histórias e rodas de leitura, atividades comuns no ambiente escolar porque a Secretaria de Educação do município mantém um projeto institucional de contação de histórias que percorre todas as escolas. Essa constatação demonstra como as políticas públicas podem possibilitar o acesso à educação estética, garantindo à comunidade escolar a participação e o efetivo envolvimento.

A segunda atividade mais colocada em prática pela escola é a expressão corporal. Dos professores, $40 \%$ afirmaram que o teatro é promovido pela escola; $20 \%$ citaram a educação física e $20 \%$, a dança. Cabe ressaltar que os professores estão entendendo por teatro qualquer atividade de encenação (dramatização) feita pelos alunos. Observamos que as atividades relacionadas ao teatro são qualitativamente expressivas, porém, quando nos referimos ao que acontece, esse dado precisaria de mais detalhes. Pela ausência de profissionais formados nessa área, compreende-se 
que há certa fragilidade na discussão desses conceitos no contexto escolar. As atividades de formação dos professores consideraram relevante essa linguagem e foram promovidas atividades teatrais; no entanto, percebe-se que na escola qualquer atividade ligada a uma "pequena apresentação" já é considerada atividade teatral, o que demonstra a necessidade de mais vivências relacionadas à linguagem cênica.

Nas artes visuais, a exposição de trabalhos e as atividades de pintura contabilizaram $70 \%$ das citações, sendo que outros $20 \%$ afirmaram promover, na escola, trabalhos com vídeos. Historicamente, as artes visuais ou, ainda, as artes plásticas estiveram presentes significativamente no contexto escolar. Compreende-se que esse dado esteja relacionado à história do ensino da arte, que marca sua presença na escola desde as atividades manuais, artesanais, técnicas, bem como à discussão dos professores de arte sobre a formação contemporânea do ensino nessa área. As propostas de ensino que promovem o uso de imagens de obras de arte na escola, como forma de articulação com a arte e a cultura, mobilizam diversos professores. Observamos esse dado, considerando a trajetória histórica dessa área de ensino. É importante ressaltar que o dado não nos possibilita inferir qualitativamente acerca do que são os trabalhos e atividades de pinturas colocados pelos professores, mas apenas indica que, das linguagens artísticas, esta é uma das mais promovidas no contexto escolar.

A música, de acordo com as respostas dos professores, é preterida pela instituição escolar. De acordo com $70 \%$ dos respondentes, é pouco usada em sala de aula, tendo sido lembradas atividades como hinos (20\%), paródias (10\%) e a música aliada a atividades de dança (10\%). Esses dados revelam que, apesar de a música ser uma linguagem artística amplamente explorada pela indústria cultural e fazer parte do cotidiano da maioria, como apontamos anteriormente, é pouco empregada como recurso pedagógico ou como elemento de educação estética na escola. Ao analisar o projeto de formação dos professores das séries iniciais, observamos que ao longo dos dois anos apenas quatro horas da temática música foram oferecidas no programa, além de duas horas de vivências musicais nos eventos, carga horária insuficiente para mobilizar os professores a vislumbrar 
possibilidades de trabalhar a música na escola. Joly (2003, p. 113) afirma que o "desenvolvimento musical está relacionado com outros processos de cognição, tais como o desenvolvimento da memória, da imaginação e da comunicação verbal e corporal". Daí a importância de a música estar presente na escola como um dos elementos formadores do indivíduo.

Apesar de as atividades artísticas nem sempre serem promovidas no ambiente escolar, foi necessário investigar a predisposição dos profissionais para essas atividades. Três perguntas foram elaboradas nesse sentido. A primeira questionava se possibilitavam aos alunos diversas atividades de contato com as artes. Dos entrevistados, $80 \%$ disseram estar preocupados em permitir o contato dos estudantes com as mais diversas artes, mas, em geral, tentavam fazer isso dentro do ambiente de sala de aula, por meio de textos, leituras, uma vez que há dificuldade de deslocá-los a espaços onde a arte ocorre. Os outros 20\% argumentaram que já existe um professor de artes que promove essas atividades, demonstrando que compreendem que a arte necessita ser trabalhada por um profissional responsável pela disciplina.

Questionados sobre as atitudes que o professor precisa ter para movimentar projetos artísticos no seu ambiente de trabalho, houve novamente um embate entre escola e profissionais. Enquanto $50 \%$ citaram a importância de o professor demonstrar atitudes criadoras, iniciativa e desenvolvimento técnico dos projetos, $40 \%$ esperavam um reconhecimento e um apoio da instituição escolar, o fim da "burocracia" e das "barreiras" impostas pela escola. Por fim, a última pergunta relacionou-se com o olhar do professor, tendo sido perguntado como o professor pode se tornar um sujeito mais sensível e que implicações esse olhar pode desencadear nas aulas. Aqui, as respostas focaram o tripé escola-professor-aluno. Dos questionados, $40 \%$ citaram a importância da modificação da escola como um todo e da valorização do profissional; outros $60 \%$ consideraram que, a partir do momento em que o professor lançar um olhar diferente sobre o aluno e perceber as suas potencialidades e talentos, poderá se tornar um sujeito mais sensível e melhorar a sua prática pedagógica. Tem esse sentido o alerta que fazem Zibetti e Souza (2007, p. 251): “Os saberes dos 
professores só podem ser compreendidos em relação com as condições que estruturam seu trabalho".

As respostas indicaram que a falta de um projeto cultural institucional impede o desenvolvimento de atividades diferenciadas, como aquelas com que tiveram contato durante o curso de formação. Conforme explica Dayrell (1996), esse embate entre instituição e profissionais faz parte de uma série de outros conflitos que constituem a instituição escolar e, dependendo da forma como ocorrem, podem trazer benefícios para a melhoria das ações escolares. Essa diferença entre professores e instituição escolar e a necessidade de negociação entre as partes, que Dayrell (1996) compreende como parte da construção social, foram constantemente citadas pelos professores.

Vale lembrar que ter acesso à arte e à cultura é um direito básico do cidadão, é garantir um padrão mínimo de qualidade de vida, como afirma Peixoto (2003, p. 46): "Quanto mais condições de acesso ao mundo da cultura - arte, filosofia e ciência —, tanto mais genuinamente humano o homem se faz". Jaeger (1994), ao apresentar a história da formação do homem na antiga Grécia, aponta como as artes eram elementos formativos do conhecimento sensível e contribuíam para a formação geral do homem, sua formação cognitiva, ética, estética e política, por enfatizarem o pensamento reflexivo e especulativo. É hora, portanto, de resgatarmos essa discussão no âmbito escolar.

\section{Mais alguns resultados: considerações finais}

E que agora em diante ia se assim: nada de vidros, cada um podia se esticar um bocadinho, não precisava ficar duro nem nada.

Dona Demência, que apesar do nome não era louca, nem nada, ainda disse timidamente:

- Mas seu Hermenegildo, será que vai dar certo?...

Ele então, não se perturbou: 
- A gente começa experimentando isso.

Depois a gente experimenta outras coisas...

E foi assim que na minha terra as escolas começaram a mudar! (ROCHA, 2011).

Promover o movimento da mudança na escola por meio da formação dos professores, semelhante àquele que podemos saborear na narrativa de Rocha (2011), não depende, evidentemente, de ações que estabeleçam um programa de formação, pois, como vimos no início deste artigo, os saberes da docência são compostos por saberes da experiência, do conhecimento e pedagógicos. Em outras palavras, "o processo de educar tem como background uma complexa malha social, histórica, pessoal e profissional que precisa ser considerada quando investigamos os saberes da docência" (NEITZEL; FERRI, 2011, p. 63).

O esforço para o estabelecimento de uma relação direta do professor com a arte, por meio de um programa, é um primeiro aspecto a ser ressaltado nesta pesquisa. A compreensão de que a arte é um dos meios possíveis para o desenvolvimento estético dos professores possibilitou a seleção de atividades que levaram em consideração o contato com obras das mais diversas linguagens da arte. No que diz respeito às mudanças que as experiências artísticas trouxeram para o currículo da escola e o repertório dos professores, $50 \%$ dos sujeitos indicaram uma mudança no currículo e 100\%, ampliações no repertório, sendo a introdução de atividades artísticas no cotidiano da escola aferida pela maioria dos professores, que apontam uma rotina que já "respira" um pouco de arte, ocasionando o alargamento da experiência estética.

Podemos afirmar que, mesmo que os professores não sinalizem claramente, há, sim, uma mudança no currículo, talvez não o currículo como matriz das disciplinas e conteúdos escolares, mas o currículo aqui compreendido como um espaço dinâmico de escolhas sociais, culturais e políticas, o que pode ser percebido no indicador acerca das atividades artísticas promovidas na escola, que revela um aumento significativo nas temáticas realizadas em música, literatura, teatro e artes visuais. 
Registramos que os professores apontaram o emprego de contação de histórias, leitura e roda de leitura, ampliando os espaços de leitura; ainda, sinalizaram que inseriram mais dramatização de histórias, capoeira, teatro, dança, ginástica rítmica e indicaram ter havido mais exposições de trabalhos realizados por alunos, pinturas, oficinas de artes, painéis, leitura de imagens e vídeos.

Diante desses dados, podemos perceber que o currículo não é apenas uma área técnica de escolha de conteúdos, mas um espaço dinâmico no qual figuram os mais diversos elementos que constituem a escola. À medida que os professores transformam o seu repertório, este interfere no que escolhem para ensinar a seus alunos, modificando significativamente a ação do professor, pois essa relação íntima entre o que se sabe e o que se ensina manifesta-se também pela concepção de arte evidenciada.

Observamos que $70 \%$ compreendem a arte como fruição, o que demonstra que os professores ampliaram sua visão e não mais a consideram um receituário a ser aplicado em sala de aula. Além disso, 30\% compreendem a arte como conteúdo. Entender a arte como fruição muda radicalmente a forma de lidar com ela em sala de aula, pois a atividade deve se centrar na apreciação e na reflexão. Isso não significa descartar a ideia de arte como conhecimento, mas não deixar de lado o aspecto estético que a constitui e procurar estabelecer o elo necessário entre o saber sensível e o conhecimento inteligível, premissa explorada por Duarte Jr. (2001).

Também percebemos que há uma luta no interior da escola para compreender o lugar da arte; ela por vezes foi vista apenas como diversão e, em outros momentos, como uma técnica a ser aplicada para o desenvolvimento de habilidades. Ainda, podemos perceber momentos no qual o conteúdo histórico e contextual sobrepôs-se à própria obra de arte. O que buscamos aqui é a ênfase na arte, na relação do sujeito com o objeto artístico, compreendendo que os saberes históricos e contextuais são parte do processo, porém não cabe a sobreposição deste à relação de fruição com a obra. Somente a aproximação com a obra de arte garante uma relação mais íntima com ela. Neitzel e Carvalho (2011, p. 114) enfatizam que "um curso de formação continuada para docentes com foco na cultura e 
na formação geral se justifica porque mais do que um elemento essencial para a reflexão, a arte contribui para ampliar o campo de percepção do sujeito pelas imersões que provoca".

Esta pesquisa sinaliza que as atividades artísticas trouxeram contribuições humanísticas e pedagógicas para a formação dos professores e aponta para a necessidade de uma educação que valorize o desenvolvimento pleno do ser humano, que perceba que os saberes sensíveis não se encontram apartados dos saberes inteligíveis, o que demanda, segundo Duarte Jr. (2001), uma compreensão de educação como um processo formativo do humano. Para esse autor, a educação possibilita ao homem desenvolver sentidos e significados que orientam a sua ação no mundo. Ainda, a educação transcende os muros da escola para o contexto cultural onde se está.

\section{Referências}

BRASIL. Lei n. 9.394, de 20 de dezembro de 1996. Estabelece as diretrizes e bases da Educação Nacional. Diário Oficial da União, Brasília, DF, 23 dez. 1996. Disponível em: 〈http://www.planalto.gov.br/ccivil_03/leis/19394.htm>. Acesso em: 19 set. 2013.

CARVALHO, C.; BUFREM, L. Arte como conhecimento/saber sensível na formação de professores. In: SCHLINDWEIN, L. M.; SIRGADO, A. P. Estética e pesquisa: formação de professores. Itajaí: Univali, 2006. p. 47-62.

DAYRELL, J. (Org.). Múltiplos olhares sobre a educação e a cultura. Belo Horizonte: UFMG, 1996.

DUARTE Jr., J. F. O sentido dos sentidos: a educação (do) sensível. Curitiba: Criar, 2001.

JAEGER, W. W. Paidéia: a formação do homem grego. Trad. Artur M. Parreira. São Paulo: Martins Fontes, 1994. 
JOLY, I. Z. L. Educação e educação musical: conhecimentos para compreender a criança e suas relações com a música. In: HENTSCHKE, L.; DEL BEN, L. (Org.). Ensino de música: propostas para pensar e agir em sala de aula. São Paulo: Moderna, 2003. p. 113-126.

NEITZEL, A. A.; CARVALHO, C. Estética e arte na formação do professor de educação básica. Revista Lusófona de Educação, Lisboa, v. 17, n. 17, p. 103-121, jan./abr. 2011.

NEITZEL, A. A.; FERRI, C. Formação continuada para professores da educação básica: metodologia do currículo integrado e laboratório de vivências pedagógicas. Revista Brasileira de Estudos Pedagógicos, Brasília, DF, v. 92, n. 230, p. 52-69, jan./abr. 2011.

NÓVOA, A. Diz-me como ensinas, dir-te ei quem és e vice-versa. In: FAZENDA, I. C. A. (Org.). A pesquisa em educação e as transformações do conhecimento. Campinas: Papirus, 1995. p. 29-41.

OLIVEIRA, S. R. R. Sobre leitura de imagens. In: ZANELLA, A. V. et al. (Org.). Educação estética e constituição do sujeito: reflexões em curso. Florianópolis: UFSC, 2007. p. 37-55.

PEIXOTO, M. I. H. Arte e grande público: a distância a ser extinta. Campinas: Autores Associados, 2003.

PORTAL, L. L. F.; FRANCISCONE, F. Contribuições da educação continuada na construção da inteireza dos docentes da educação superior. Educação, v. 30, n. 3, p. 557-569, set./dez. 2007.

ROCHA, R. Este admirável mundo louco. Ruth Rocha, Histórias, 2011. Disponível em: <http://www2.uol.com.br/ruthrocha/historias_18.htm>. Acesso em: 10 mar. 2011.

ROSE, D. Análise de imagens em movimento. In: BAUER, M. W.; GASKELL, G. (Org.). Pesquisa qualitativa com texto, imagem e som: um manual prático. 2. ed. Petrópolis: Vozes, 2003. p. 343-364. 
SCHAFER, R. M. O ouvido pensante. Trad. Marisa Trench de O. Fonterrada, Magda R. Gomes da Silva e Maria Lucia Pascoal. São Paulo: Unesp, 1991.

VEIGA, I. P. A. (Org.). Projeto político-pedagógico da escola: uma construção possível. 26. ed. Campinas: Papirus, 2009.

VIGOTSKI, L. S. Psicologia da arte. Trad. Paulo Bezerra. São Paulo: Martins Fontes, 1999.

ZIBETTI, M. L. T.; SOUZA, M. P. R. Apropriação e mobilização de saberes na prática pedagógica: contribuição para a formação de professores. Educação e Pesquisa, v. 33, n. 2. p. 247-262, maio/ago. 2007.

Recebido: 16/08/2011

Received: 08/16/2011

Aprovado: 23/09/2011 Approved: 09/23/2011 